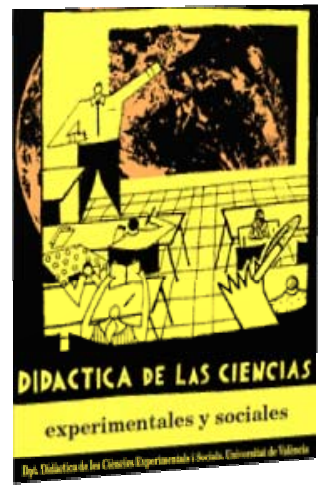

\title{
Originalidad, desarrollo y destrucción de la historiografía progresista en la educación primaria española (1931-1939)
}

\author{
Originality, development and destruction of \\ progressive historiography in Spanish primary \\ education (1931-1939)
}

DOI: $10.7203 / D C E S .36 .12922$

\author{
Javier Esteve Martí \\ Universidad de Chile (Chile), jaesmar87@gmail.com
}

RESUMEN: La proclamación de la Segunda República implicó importantes reformas en el terreno de la educación en España. Pero la brevedad de la experiencia republicana impidió la superación completa del modelo educativo tradicional. Sí se produjo un aumento del número de manuales escolares afectos a la historiografía progresista, en un fenómeno violentamente atajado por la guerra y la dictadura. En este texto se analizan los manuales escolares progresistas de Eladio García Martínez y Modesto Medina Bravo y el de Daniel González Linacero con el objetivo de definir su filiación con obras e intelectuales anteriores, señalar las continuidades y novedades que se plasmaron en sus páginas y prestigiar la labor didáctica y pedagógica de sus autores frente al retroceso cultural que supuso el franquismo.

Palabras ClAve: Educación, manuales escolares, historiografía progresista, Segunda República, Franquismo.

ABSTRACT: The proclamation of the Second Republic implied important reforms in the field of education in Spain. But the briefness of the Republican experience prevented the complete overcoming of the traditional educational model. Certainly, there was an increase in the number of textbooks affiliated to progressive historiography, in a phenomenon violently blocked by war and dictatorship. In this article the progressive textbooks of Eladio García Martínez and Modesto Medina Bravo, and that of Daniel González Linacero, are analyzed with the aim of defining their relationship with previous works and intellectuals, pointing out the continuities and novelties embodied in their pages and giving prestige to the didactic and pedagogical work of its authors in front of the cultural setback that the Francoism brought about.

KEYWORDS: Education, textbooks, progressive historiography, Second Republic, Francoism.

Fecha de recepción: julio de 2018 Fecha de aceptación: febrero de 2019

El autor expresa su gratitud hacia todos los que convirtieron su travesía en el campo de la didáctica de las Ciencias Sociales en una experiencia satisfactoria, aunque especialmente a Antonio, David, Juan Carlos y Carlos, al último de los cuales también agradece sus comentarios a la primera versión de este artículo. 


\section{INTRODUCCIÓN}

El 14 de abril de 1931 arrancó una nueva fase de la historia de España: tras cerca de medio siglo de un liberalismo oligárquico que falsificaba la representatividad popular y más de siete años de dictadura, la caída de la monarquía parecía señalar la hora de emprender la construcción de un régimen democrático que satisficiese los deseos de justicia social y elevación cultural de buena parte de la sociedad española. Pero la empresa, en el contexto de las tensiones, contradicciones y dificultades del periodo de entreguerras, era difícil. En consecuencia, la Segunda República (19311939) fue un periodo de grandes esperanzas, pasiones y agitaciones, en el que muchas de las transformaciones anheladas apenas superaron los primeros pasos.

En el campo de la educación primaria la proclamación de la República vino acompañada de una fuerte inversión económica cuyo objetivo era aumentar el número de escuelas, que a todas luces era insuficiente para acometer el necesario incremento del porcentaje de población escolarizada. Es cierto que las previsiones de primera hora, muy optimistas, chocaron con dificultades financieras y obstáculos de orden político, pero a pesar de ello el esfuerzo del nuevo régimen no contaba con precedentes en la historia de España. También fue destacable el capital invertido por los primeros gabinetes republicanos para retribuir mejor a los maestros e incrementar rápidamente su número. A tal fin se modificó la forma de acceso a la planta docente, en un proceso que no sólo se saldó con cambios cuantitativos, sino también cualitativos. Y es que la supresión de las oposiciones fue acompañada de una drástica reforma de las Escuelas Normales en las que se formaba a los maestros. Éstas no sólo aumentaron numéricamente, sino que en ellas se comenzó a exigir el título de bachiller como requisito previo, se estableció un régimen de coeducación y se implantó un plan de estudios que, marcado por el deseo de profesionalizar la labor educativa, incluía tres años de formación académica y un curso completo de prácticas remuneradas.

Característica del periodo republicano fue también la reforma de la Inspección de Primera Enseñanza, que supuso la conversión de los inspectores -antaño elementos de vigilancia de la administración pública- en asesores y alentadores de la labor educativa de los maestros. No menos importantes fueron las reformas cuya meta era profundizar en la laicización del sistema educativo. $\mathrm{Y}$ es que el decreto de libertad religiosa, que garantizaba la libertad de conciencia, eliminó la enseñanza de la religión como materia obligatoria en todos los centros de educación primaria. Además, la República prohibió -aunque con limitada efectividad- el ejercicio del magisterio a las órdenes religiosas. En consecuencia, el periodo republicano supuso un importante avance en la implantación del laicismo en la educación, proceso que fue paralelo al fortalecimiento de la función docente del Estado, que potenció una educación laica, gratuita, en régimen de coeducación y con carácter social. Igualmente significativas fueron las concesiones de la República favorables al bilingüismo y a la autonomía educativa catalana (Pérez, 1988; Molero, 2005).

En el mundo rural tuvo especial impacto la creación de las Misiones Pedagógicas, instituidas para favorecer el acceso a la cultura de las comarcas aisladas (Otero, 1982; Tiana, 2016). Esta empresa, inspirada por Manuel Bartolomé Cossío -que también dirigió la Institución Libre de Enseñanza (ILE)- contó, entre otros, con el concurso del profesor y director de la Escuela Normal de Palencia Daniel González Linacero y de los inspectores de primera enseñanza Eladio García Martínez y Modesto Medina Bravo, todos ellos relevantes en este texto. El primero de ellos, militante socialista, participó en varias misiones en la provincia de Palencia. A su vez, E. García colaboró en una única campaña cuyo objetivo fueron varias aldeas de la Sierra de Guadarrama. Mucho más importante fue la implicación de M. Medina, que tras haber cursado Magisterio ejerció como inspector de escuelas rurales de la provincia de León entre 1923 y 1931. Como tal, en repetidas ocasiones denunció el lamentable estado de la educación en las áreas rurales (Gómez y Romero, 2007: 202), razón por la que durante la República se convirtió en delegado del Patronato 
de las Misiones Pedagógicas. Como tal participó en campañas en Madrid, Huesca, Segovia, Ávila, Granada y Jaén ${ }^{1}$.

En todo caso, ni los escasos seis años en los que coincidieron democracia y paz, ni la abundancia de cambios de gobierno favorecieron transformaciones tan profundas como cabría esperar. En especial porque los gobiernos radicales y cedistas del segundo bienio republicano sabotearon la labor educativa del gobierno provisional y de los primeros gabinetes de izquierdas. De hecho, redujeron la inversión estatal, recondujeron la reforma de las Escuelas Normales, facilitaron que los miembros de las órdenes religiosas impartiesen docencia y rectificaron la autonomía educativa catalana. Aunque el Frente Popular prometió volver a la senda del primer bienio republicano, su empeño se vio frenado por el golpe de Estado (Pérez, 2000).

Una de las tareas que por la brevedad y agitación de la experiencia republicana quedó pendiente fue la superación completa de un modelo educativo tradicional que, entre otras cosas, se reflejaba en los manuales escolares de historia. Nos referimos a una enseñanza que respondía a una concepción suntuaria de la cultura y en la que las finalidades instructivas predominaban sobre las estrictamente educativas. En consecuencia, los manuales escolares tradicionales pretendían formar discentes dóciles y respetuosos con el orden y las jerarquías, lo que se perseguía a través de la definición de dicha conducta como propia de buenos católicos y patriotas. Por tanto, los contenidos eran seleccionados en atención a su capacidad para transmitir la idea de una España inherentemente católica y monárquica, depositaria de valores inmutables. Asimismo, los textos escolares tradicionales transmitían un relato historicista, cronológico y teleológico en el que imperaban los grandes personajes y los acontecimientos político-militares, aprendidos de forma memorística (Cuesta, 1997).

Los límites de la experiencia republicana se tradujeron en la habitual reutilización de libros de texto de periodos anteriores. Es decir, a pesar de los esfuerzos reformistas, una parte importante de los manuales escolares de historia continuaron siendo los mismos y por tanto, difundiendo los valores que habían imperado en períodos anteriores. Ahora bien, en esta etapa se produjo el fin de la hegemonía casi absoluta de las obras de inspiración conservadora, tradicionalista y neocatólica (López, 2008: 173). La pretensión de formar una cultura cívica republicana llevó a los gobiernos progresistas a impulsar la escuela pública y en ese contexto, pese a la tónica de continuidad, proliferaron obras que trataban de superar la historiografía heroico-individualista. Pero el golpe de Estado de 1936 y la posterior victoria rebelde, que no permitieron asentar las reformas educativas republicanas, también hicieron imposible completar la revolución de la historiografía escolar (Valls, 1997 y 2007), que sufrió una involución brutal.

\section{LA HISTORIA EN LOS LIBROS DE TEXTO DURANTE EL PERIODO REPUBLICANO}

Durante la segunda mitad del siglo XIX los manuales escolares de historia se fueron alineando, grosso modo, en torno a dos grandes escuelas. Por un lado, la tendencia mayoritaria, en la que coexistían elementos liberal conservadores, tradicionalistas, integristas y neocatólicos. Por el otro, una amalgama de corrientes intelectuales liberal-progresistas, krausistas, institucionistas y regeneracionistas. En las primeras décadas del siglo XX, la crisis económica, social y política no hizo sino agudizar las diferencias entre dichas escuelas historiográficas. Más adelante, en las décadas que van de los años treinta a los setenta se produjo, en distintos momentos, el periodo álgido de cada una de ellas. La historiografía progresista encontró un contexto favorable durante la República, aunque en ella no se persiguió a la historiografía ultramontana, que sí gozó de absoluta preeminencia bajo la dictadura.

Durante el periodo republicano hubo numerosos manuales escolares que patentizaron la continuidad respecto a etapas anteriores. Así sucede en trabajos como el de J. Ibáñez y L.

\footnotetext{
${ }^{1}$ Sobre la participación de E. García, M. Medina y D. González en distintas campañas de las Misiones Pedagógicas, véase http://cipres.residencia.csic.es/misiones/index.php [24 de febrero de 2019]
} 
Cemborain (1935). Éste permite observar una continuidad que, además, parte de una concepción tradicionalista de la historia. También resulta sencillo encontrar obras en las que elementos relativamente innovadores chocan con la inercia de un savoir-faire obsoleto. Éste sería el caso del texto publicado por E. Solana (1931). En él se hacía una concesión a la didáctica coetánea al aceptarse la necesidad de entrelazar patrimonio e historia. Pero también eran detectables arcaísmos como la mención a un “carácter” español atemporal o la interrelación de los primeros habitantes de la Península con los descendientes de Noé (Solana, 1931: 29).

\subsection{La Historia de España de Eladio García Martínez y Modesto Medina Bravo}

Pero además de manuales escolares ultramontanos e híbridos, también hubo textos de orientación progresista. Un buen ejemplo lo constituye Historia de España, obra publicada en 1934 por E. García y M. Medina. De hecho, el posicionamiento de este libro de texto redactado para el último grado de la educación primaria ha sido calificado en estos términos (Gómez y Romero, 2007: 202). Lo ha sido por su orientación didáctica y pedagógica -que se materializaba en las instrucciones al profesorado, en sus ejercicios y en la pretensión de complementar el texto con una amplia batería de fuentes-, pero también por su renuncia a una historia factual y estrictamente política o por la promoción de valores progresistas. Esta obra y las dos de D. González que serán analizadas más adelante resultan representativas de la historiografía escolar progresista -y por ello han sido elegidas en este artículo- tanto por la difusión que alcanzaron como porque el dispar destino de sus autores las convierte en ejemplos paradigmáticos del devenir de dicha escuela historiográfica a partir de 1936.

En las instrucciones al profesorado de Historia de España se calificaba como fundamental el uso de "textos de las obras maestras de la literatura" o "la visita a monumentos, museos e industrias antiguas y modernas”. También se recomendaba el empleo de fotografías, grabados, mapas o recortes de prensa para reforzar la visión histórica del alumnado. Además, se atribuía poder evocador a las construcciones manuales realizadas por el discente. Todo ello porque "lo esencial es convertir el estudio de la Historia en algo vivo, que dé al niño una clara visión de la evolución y de la solidaridad humanas y le haga sentirse vinculado con sus semejantes para la obra común de continuar el progreso moral y cultural de la especie” (García y Medina, 1934: 13-14). Por tanto, se disponía una batería de recursos pedagógicos y didácticos que buscaban convertir al discente en participante de la construcción del conocimiento. Además, la meta de formar españoles era compatible con la de preparar ciudadanos solidarios y demócratas.

En cuanto a los ejercicios o "sugestiones", su planteamiento refuerza lo apuntado. Por ejemplo: "estúdiese la choza de nuestros pastores y piénsese en lo que sería la del hombre primitivo”; "léanse los títulos preliminar y $3^{\circ}$ de la Constitución de 1931, y compárese su contenido con la declaración de los Derechos del Hombre"; "léanse periódicos de distintas tendencias y acostúmbrese a los niños a juzgar sin apasionamientos, con respeto para las creencias ajenas". Desde luego, no eran cuestiones que pudiesen solucionarse con la mera repetición del texto de la obra. Además, en el caso de la última, de nuevo queda claro que una de las metas era formar individuos capaces de vivir en libertad y democracia.

Respecto a las imágenes, éstas iban acompañadas de una descripción que las convertía en verdaderos documentos, aunque las actividades no solían referirse a ellas (Valls, 1995). Por otro lado, en esta obra se trataba intensamente lo que entonces se conocía como "historia interna". Un buen ejemplo es que cuando se hacía referencia al inicio de la época moderna se concedía espacio al Renacimiento, el humanismo, los libros, el idioma, el arte, las costumbres o las festividades (García y Medina, 1934: 153-159). O lo que es lo mismo: se invertía un buen número de páginas en tratar sobre el desarrollo de la cultura material, aunque sin alcanzar el nivel que se observará en D. González (García y Medina, 1934: 19-21). 
Pueden destacarse los títulos de dos de los capítulos de esta obra. El primero, "Lucha por el mejoramiento social y político", incluía temas como la revolución inglesa y francesa o la lucha contra el absolutismo de las Cortes de Cádiz (García y Medina, 1934: 200-205). En esta lección se observaba al pueblo, auténtico protagonista de la historia, luchando por la soberanía. Asimismo, se reconocía la trascendencia de la declaración de los derechos del hombre. El siguiente capítulo, "Lucha por la igualdad social y económica”, recogía la aparición del socialismo, el comunismo y el sindicalismo. En él, los autores apreciaban las "conquistas proletarias" y un "movimiento social” que "aspira [...] a atenuar las diferencias económicas y a garantizar a todos, mediante el trabajo, una existencia digna” (García y Medina, 1934: 215-216).

Por último, merece un breve comentario el capítulo dedicado a la Segunda República. En él se hacía mención al sistema político turnante, al caciquismo y a los problemas regionales, sociales, económicos y culturales de la Restauración. Los autores indicaban al discente que "nadie que tenga idea de los atributos de su humanidad puede consentir que otro disponga de su albedrío, anulando su personalidad". Por tanto, criticaban a una monarquía que "no supo vivir buscando en el pueblo la razón de su existencia” (García y Medina, 1934: 218-221). Y es que también durante esta etapa legitimar el régimen existente -en este caso una república democrática- era una de las finalidades de los manuales escolares.

\subsection{Los manuales escolares de Daniel González Linacero}

También merecen atención Mi primer libro de historia -destinado al primer grado de la educación primaria- y Mi segundo libro de historia -orientado al segundo-, obras en las que D. González planteaba un tratamiento de la historia antagónico al de los textos centrados en personalidades (González, 1933 y 1934). En éstas, como en las de autores como J. Izquierdo (1934), los protagonistas eran los objetos y los avances técnicos. En particular, se estudiaban temas -o centros de interés- como la vivienda, el vestuario, la caza y las armas, los medios de transporte, el alumbrado, el trabajo, los juegos, la cultura escrita y las relaciones político-económicas. El primer manual contaba con un capítulo introductorio titulado "Nuestra vida", mientras el segundo introducía dos nuevos centros de interés: la religión y el arte. En ocasiones se ha señalado que una de las debilidades de los trabajos de D. González fue la desconexión entre estas categorías de la actividad humana (Boyd, 1997: 216-217).

Además del planteamiento individualista, también se ponía en cuestión la primacía absoluta de la orientación cronológica. Y es que el uso de centros de interés llevaba a emplear un método cíclico con el que se cubría varias veces la historia de la humanidad. Pero la ruptura no era absoluta: cada capítulo seguía una secuencia ordenada ${ }^{2}$ en la que el tiempo histórico se demarcaba en los periodos prehistórico, oriental, clásico, medieval, renacentista y actual (González, 1934: 8 y Aparicio, 1990: 479). Estas rupturas, relativas, resultan previsibles si se atiende a la crítica que D. González (1933: 61-62) hizo de la historiografía escolar hegemónica:

Por doquiera, libros históricos amañados con profusión de fechas, sucesos, batallas y crímenes; relatos de reinados vacíos de sentido histórico; narraciones de acontecimientos militares, todo bambolla y efectismo espectacular [...] Despertando en el niño el instinto de lucha y glorificando hasta la categoría de héroes a aquellos muñecos trágicos que morían desconociendo la razón de su sacrificio, el niño adquiere un sentido falso del valor moral, individual y colectivo. Nunca se cuidó el educador de borrar toda esa balumba insoportable de necedades de príncipes y favoritos, extrayendo del evolucionar histórico aquellos sucesos de orden material y espiritual que de una manera indudable han contribuido a formar este mundo que nos rodea, sin olvidar que la Historia no la han hecho los personajes, sino el pueblo todo y principalmente el pueblo

\footnotetext{
${ }^{2}$ A modo de ejemplo, véanse los epígrafes dedicados en su primer libro a la vivienda, en los que se va de la cueva de Antequera a los rascacielos neoyorquinos; y al vestido, que abarca desde los ropajes hechos con hojas y pieles hasta la moda actual (González, 1933: 15-25).
} 
trabajador humilde y sufrido, que solidario y altruista, ha ido empujando la vida hacia horizontes más nobles, más justos, más humanos.

Tras leer este texto, no sorprende que sus trabajos se orientasen de acuerdo con una narrativa de progreso que también era visible en E. García y M. Medina. Tampoco extraña que en sus manuales escolares hubiese una importante disminución de los nombres propios y las fechas. De hecho, en otra de sus obras, dedicada a la historia del arte, cuando se trataba sobre la construcción de la catedral de Burgos se hacía referencia a su promotor -Fernando III- y su principal arquitecto, pero también a los obreros que la levantaron (González, 1936). Resulta evidente el deseo de superar las individualidades, aunque -adelantándonos a puntualizaciones que haremos en el siguiente epígrafe- este empeño debe asociarse a la evolución de la sociología (Alario, 1986: 51-52).

Tampoco fueron rupturistas -en atención a lo ya visto en E. García y M. Medina- las actividades propuestas por D. González. Al plantearlas señaló que lo hacía para evitar que el profesorado cayese en “viejos arcaísmos pedagógicos”. Para ello dispuso ejercicios que requerían la realización de redacciones, dibujos, mapas o trabajos manuales (González, 1934: 9). En cuanto a las imágenes, eran dibujos sencillos con una finalidad ilustrativa. Por otra parte, en el manual escolar orientado al primer grado, pensado para niños de entre ocho y diez años, se empleaba una tipografía grande y un vocabulario básico. En cuanto al libro para segundo grado, con un público objetivo de entre diez y doce años, su texto era más extenso y su vocabulario más rico, aunque los términos más complejos se explicaban al final de la obra (Boyd, 1997: 216-217).

Aun así, la principal diferencia entre ambas obras era que en la segunda se incluyeron biografías como cierre de cada uno de los centros de interés. Puesto que uno de los objetivos era romper con un modelo de historia individualista, se justificó la decisión: "lo estimamos necesario por pensar que la época produce grandes hombres, que al ir surgiendo de la masa innominada, el verdadero sujeto de la historia, se van convirtiendo en dirigentes geniales de un proceso íntimo y causal que va encauzando la vida de los pueblos hacia un indudable progreso, jamás interrumpido" (González, 1934: 7-9). Una vez más, la importancia de la narrativa de progreso resulta innegable. En cuanto a los biografiados, Miguel Ángel, Jacquard, Stephenson, Edison, Gutemberg, Pablo Iglesias, Milón de Crotona, Goya y Jesucristo eran los personajes que, debido a su relevancia artística, técnica, deportiva, social e incluso religiosa se hicieron acreedores de protagonizar los centros de interés relativos a la vivienda, el vestuario, los medios de transporte, el alumbrado, la cultura escrita, el trabajo, los juegos y el arte, respectivamente. Para el apartado relativo a la caza y las armas no había biografiado y para el de las relaciones políticas y económicas el elegido no era una persona, sino la Sociedad de Naciones (González, 1934: 168).

No era casualidad, pues D. González, pacifista ${ }^{3}$, defendía la importancia de las organizaciones internacionales, pero también hacía hincapié en que los textos escolares debían dejar de considerar héroes "a los que nos mostraron su valor temerario en los campos de batalla". Para él, había que acabar con la "literatura de arenga [...] que hace crecer el entusiasmo por la destrucción y la matanza” (García, 1986: 34-35). Dichas ideas influían en un "panteón heroico” en el que abundaban inventores, hecho que además recuerda la importancia otorgada a la cultura material. Como cierre al capítulo dedicado a las religiones, el elegido era Jesús, lo que tenía sentido en una España en la que, durante la primera mitad del siglo XX, no existía -excepto en las posesiones coloniales norteafricanas- ninguna religión con arraigo que no fuese la católica. D. González tenía una visión positiva de las religiones, pues consideraba que "todas preconizan y aconsejan la justicia, la bondad, la solidaridad, el trabajo, la fraternidad” y "condenan la avaricia, la mentira, el orgullo, la soberbia, la holgazanería y el crimen”. Para él, esto demostraba la existencia de principios morales universales (González, 1934: 139).

\footnotetext{
${ }^{3}$ En el apartado relativo a la caza y las armas se planteaba como actividad "pensar por qué la caza dejó de ser una necesidad, y por qué la guerra es una gran desgracia” (González, 1934: 53).
} 
Igualmente destacable resulta la inclusión entre los biografiados de Pablo Iglesias, del que se afirmaba que tuvo una "existencia ejemplar" y que "con la vista puesta en una idea, se entregó por entero al mejoramiento espiritual y económico de los trabajadores españoles” (González, 1934: 112). Este caso sería demostrativo de la fragua de un panteón cívico republicano y democrático. Y es que su figura también era elogiada por E García y M. Medina (1934: 215-216), que lo calificaron de "creador del socialismo español, obra de su fe de apóstol, de su perseverancia y de su vida ejemplar”. En realidad, su caso no era único: en la nómina de héroes liberales, progresistas, republicanos o demócratas también sobresalían las Cortes de Cádiz, Pi i Margall o Castelar (Boyd, 1997).

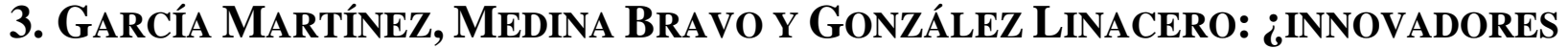 AISLADOS O HEREDEROS DE UNA TRADICIÓN ACRISOLADA?}

Un libro de texto interesante para mi argumentación es la Historia de España de Juan Bosch Cusí. Aprobado en 1909, seguía editándose en 1933, anotándose en su prólogo que el estudio de la historia "ya no se limita, como antaño, a la historia externa o política, esto es, guerras, conquistas, cambios de dinastías y sucesión de reinados; sino que comprende también la historia interna o de la civilización”. En él también se aconsejaba al maestro usar grabados, láminas o mapas y hacerse servir de "ejercicios de vocabulario, investigación, juicio y raciocinio". Además, se afirmaba que "las visitas a los museos arqueológicos y los paseos escolares a los sitios que recuerdan tiempos o hechos memorables, son recursos pedagógicos [...] insustituibles”.

Ahora bien, todo ello debía emplearse "con el fin de despertar y desarrollar los sentimientos patrióticos”. Persistía, por tanto, un planteamiento orientado de forma casi exclusiva a la formación del alumnado en el nacionalismo español. Un nacionalismo que se afirmaba en planteamientos intransigentes cuando iba unido a afirmaciones xenófobas. Así ocurría en la lección intitulada "Dominación musulmana”, en la que se definía un carácter árabe "indolente [...] astuto, hipócrita y vengativo". De hecho, en lo que resulta una interpretación histórica sorprendente, se señalaba que los árabes que llegaron a "España”, se encontraron "con un pueblo envilecido, pero muy superior al suyo en civilización”. Ello explicaría la supuesta "sumisión de los árabes a la cultura española” (Bosch, 1933: 36-42). Ello no quita que en esta obra hubiese una llamada a superar la historia política y a considerar al discente como parte activa en el proceso educativo.

En esto J. Bosch conectaba con R. Altamira. Este ferviente regeneracionista ya se preocupó por el valor social del conocimiento histórico. Precisamente por ello denunció la enseñanza memorística y dogmática. También propuso el aprovechamiento de los vestigios del pasado. Así, más de treinta años antes de las obras de E. García, M. Medina y D. González, R. Altamira hizo hincapié en la importancia de los documentos, monumentos o museos como recursos didácticos. Por otro lado, en sus escritos también podía encontrarse una llamada a complementar el estudio de la historia política -o externa, como la denominaba- con el de la historia de la civilización o interna (Altamira, 1981; Valls y López, 2011: 195).

Todo esto no debe llevar a subestimar trabajos como los de E. García y M. Medina o D. González. En el caso de este último, Mi primer libro de Historia fue elogiado por el maestro socialista Pablo Cortés Fauré o por la pedagoga feminista María Luisa Navarro Margati, pero también por el fascista Enrique Herrera Oria o por Agustín Serrano de Haro, uno de los autores de manuales escolares de historia más activos durante el franquismo (Escudero, 1999: 90). También resulta significativo que dicho libro agotase, en dos años, una edición de diez mil ejemplares (Mainer, 2009: 218-219). Ahora bien, no es recomendable caer en el tono exageradamente encomiástico con el que muchas veces se ha caracterizado la obra de D. González. A modo de ejemplo, P. García (1986: 31) la definió como “actual”, “novedosa” e incluso “excepcional”.

Parece más lógico interpretar los esfuerzos de estos autores en relación al contexto en el que se movían. Así, en el caso de D. González debe tenerse en cuenta que -como ha señalado C. García 
(1986: 16-17)- en Palencia existía representación de las dos grandes escuelas historiográficas. Por un lado, estaba la impulsada por el obispado, los sindicatos católicos y los maestros de la escuela del Ave María. Por el otro, los elementos afines a la Escuela Nueva y a la ILE, integrados en una Asociación Provincial de Maestros que colaboró con las Misiones Pedagógicas. Si tenemos en cuenta el contexto se hace evidente que muchas de las innovaciones que se atribuyen a D. González no fueron tales. Y lo mismo ocurriría en el caso de E. García y M. Medina.

Ya se ha apuntado que no eran pioneros al plantear la historia como una materia que debía tener valor social. Otra cosa es que, al pretender poner la enseñanza de la historia al servicio de la humanidad, lo hiciesen defendiendo una profunda transformación social. En esta línea, sus obras presentaban una visión del pasado que impulsaba al discente a luchar por un mundo más justo y pacífico. Ello no implica que sus trabajos no participasen de un discurso nacionalista español, aunque éste fuese diferente al que difundía la historiografía escolar ultramontana (Parra y Segarra, 2018). En este sentido, el nacionalismo podía sobreponerse incluso a la concepción universal de la historia de D. González, que redujo el volumen de referencias a comunidades concretas y a temas específicamente españoles (Boyd, 1997: 216-217).

El nacionalismo cívico, tolerante y empapado de humanitarismo internacionalista también era una característica que compartían con otros autores. Y es que en el nacionalismo regeneracionista de R. Altamira ya había una encomiable ausencia de xenofobia y beligerancia que ha llevado a definirlo como una respuesta optimista al discurso de las naciones moribundas (de la Torre, 1985). Por otra parte, las instituciones republicanas se esforzaron por cultivar un determinado modelo de nacionalismo. Ello quedó patente con la concesión del Premio Nacional de Literatura a Estampas de España, obra en la que F. J. de Larra (1933) no celebraba a los protagonistas de las glorias imperiales tradicionalmente exaltados, sino a los “españoles” que, a lo largo de la historia, habían destacado por virtudes compatibles con un nacionalismo democrático (Boyd, 2003: 164-165).

Como ya se ha apuntado, centrar el análisis en la progresión de la humanidad en los planos material y social no era novedoso. De hecho, el mismo D. González reconoció el ascendiente que sobre él tenían las “lecciones de las cosas” del francés R. Cousinet, representante de la éducation nouvelle. Si acaso, D. González se caracterizaba por una ferviente confianza en el progreso que, en realidad, tampoco era original. Y es que en su obra imperaba la tesis de que la progresiva conquista humana del medio físico habría creado las condiciones materiales -fundamentales de acuerdo con los planteamientos del materialismo histórico que practicaba la intelectualidad socialista en que se encuadraba Linacero- adecuadas para la evolución de las ideas políticas, religiosas o sociales. Así, cada uno de sus centros de interés estaba marcado por la idea de que el presente era superior al pasado debido al progresivo desarrollo de valores como la tolerancia o la cooperación (Boyd, 1997: 216-217 y 2003: 164).

$\mathrm{M}^{\mathrm{a}} \mathrm{T}$. Alario apuntó que D. González anticipó los postulados de la educación desde el medio, que propone el estudio del entorno próximo como herramienta capaz de motivar al discente, permitiendo posteriores comparaciones y generalizaciones con espacios más amplios. Pero ello no impidió que la misma $\mathrm{M}^{\mathrm{a}} \mathrm{T}$. Alario (1986) señalase la evidente relación de la metodología de D. González con la de intelectuales como Manuel Bartolomé Cossío. A su vez, M. García (2008: 52) apuntó que los trabajos de D. González suponían "un precoz ensayo de historia social adaptado a las modestas aptitudes de los pequeños lectores”. Pero como ya ha apuntado P. García (1986: 30-31), su estudio de la evolución del plano material, ideológico y cultural también era una respuesta al descrédito de la historia factual. Y puesto que la Escuela de los Annales ya era una realidad, que la narración histórica sobrepasase el ámbito político no era excepcional.

En cuanto a las propuestas didácticas de E. García, M. Medina y D. González, éstas tenían por meta que el discente desarrollase un pensamiento crítico. Precisamente por ello, las actividades que proponían fomentaban su participación en la construcción del conocimiento a través de métodos como la observación o el análisis. Asimismo, la naturaleza de los ejercicios era interdisciplinar y no se restringía al espacio físico del aula. Todo esto era encomiable, especialmente si lo comparamos 
con lo que ocurriría a partir del 1 de abril de 1939. Pero no era revolucionario: los principios pedagógicos que les inspiraban enlazan con los de la escuela nueva y activa y con los de una ILE que ya contaba con más de medio siglo de vida. Por último, la oposición a la guerra no denotaba más que el horror con que toda una generación había asistido a la Gran Guerra, conflicto bélico en el que los impresionantes avances técnicos se pusieron al servicio de la destrucción y la muerte.

\section{LA CAÍDA DE LA HISTORIOGRAFÍA ESCOLAR PROGRESISTA}

El 8 de agosto de 1936, apenas iniciada la Guerra Civil, D. González fue asesinado por un grupo de falangistas. Actualmente sus restos aún continúan desaparecidos, probablemente enterrados en algún punto de la carretera que une Arévalo (Ávila) y Valladolid (García, 2008: 52). M. Medina corrió mejor suerte: salvó la vida, aunque terminada la guerra fue procesado por “auxilio a la rebelión”. Su expediente de depuración laboral -en el que se le acusó de participar en la organización del Sindicato Nacional de Inspectores y Profesores de Normal (Jiménez, 2003: 208)- se saldó con su baja del escalafón de inspectores de primera enseñanza. Tras sobrevivir merced a variopintos oficios, sólo en 1941 halló colocación en la editorial Espasa-Calpe (López y Medina, 1978: 62-64).

La muerte de D. González y la preterición de M. Medina patentizan la represión en la zona sublevada primero y en la España franquista después y la depuración del sector educativo, proceso que formaba parte de las prácticas represivas (Fernández y Agulló, 1999). Pero el franquismo no se conformó con robar la vida o el sustento a estos funcionarios públicos: también determinó su damnatio memoriae académica. Así, cuando aún en 1938 se publicaron listados con los libros que debían autorizarse o prohibirse en las bibliotecas escolares ubicadas en territorio rebelde, todos los trabajos de D. González se incluyeron en el número de los segundos (Sotomayor, Cerrillo, Sánchez y Cañamares, 2016: 67).

En el caso de M. Medina resulta notable lo ocurrido con La Enseñanza de la Historia en la Escuela Primaria, trabajo que en 1936 había formado parte del Libro-Guía del Maestro. En la segunda edición de este escrito, que elaboró junto a E. García, su firma desapareció. No fue el único cambio en la versión publicada en $1941^{4}$. De hecho, se ha destacado que en el interior del LibroGuía este trabajo fue el que sufrió mayores alteraciones. Entre ellas la supresión de referencias a autores como Rafael Altamira, Gloria Giner, Manuel Bartolomé Cossío y el mismo Daniel González Linacero (Mainer, 2009: 517-518). Por tanto, puede afirmarse que más allá de la depuración física y laboral del sector educativo, D. González y M. Medina simbolizan otro hecho remarcable, igualmente consecuencia de la implantación de la dictadura: el de la abrupta desaparición de una de las dos grandes corrientes de la historiografía escolar.

La dictadura aniquiló la orientación progresista de la enseñanza y en consecuencia el pensamiento clerical y reaccionario halló en los nuevos libros de texto un campo abonado para su desarrollo (López, 2008: 175). En este periodo -marcado por la imposición de una ideología monolítica- fue difícil la supervivencia de obras anteriores, pues incluso las marcadamente ultramontanas hubieron de hacer frente a cambios. En primer lugar, se produjo un rechazo virulento de la "historia interna" y las "lecciones de cosas". Un buen ejemplo de los trabajos que se impusieron lo encontramos en A. Serrano, que apuntó que las cosas inertes no podían competir con héroes y santos en el empeño de inculcar en el discente un patriotismo que era objetivo principal de la educación (Serrano, 1942: 5-6). Por otro lado, el nacionalismo franquista era agresivo: el pacifismo desapareció de los manuales escolares tras 1939. De hecho, La Enseñanza de la Historia en la Escuela Primaria (1941) llamó a subrayar los hechos bélicos en los que el pueblo español demostraba su supuesta dignidad e independencia (Aguilar, 2002: 60).

\footnotetext{
${ }^{4}$ Una versión que ha sido definida como propaganda del nuevo régimen (Ruiz, 2002: 61).
} 
Además, también se produjo la proliferación de obras en las que la historia se convertía en un género literario ajeno al análisis documental. De hecho, el embate de fenómenos como el providencialismo tuvo graves efectos en el rigor de la historia enseñada. Así lo demuestra lo anotado por A. Serrano en Yo soy Español, libro significativo del periodo: "queremos que empiecen a oír los nombres ejemplares y las gestas heroicas; que las cosas de Dios y España entren [...] en [...] su conciencia. Mas no precisamente para que sepan [...] ¡también tiene su importancia el sentir!”. La imposición de manuales escolares como éste conllevó el retorno de la historia política, la definición del discente como sujeto pasivo, el relajamiento del rigor historiográfico y el predominio de una labor didáctico-pedagógica que se sintetizaba en la única recomendación que A. Serrano (1942: 5-6) daba a los maestros: "ama tú mucho a España y encontrarás recursos infinitos para enseñar a los niños a que la amen”. Además, frente a los balbuceos de construcción de un panteón transnacional, cultural y democrático, el franquismo devolvió la centralidad a guerreros, clérigos y monarcas, a los que se unieron los héroes de la “cruzada” (Muntada, 1942: 306-312; Serrano, 1942).

En atención a todo esto, no resulta sorprendente la ruptura con una escuela que concebía la historia como un camino hacia la libertad y la igualdad o que propendía a principios solidarios y universalistas heredados de la Ilustración, el liberalismo o el marxismo. Así, la ruptura con la corriente historiográfica aquí representada por E. García, M. Medina y D. González no causa asombro. Tras esta quiebra había razones ideológicas: estos autores centraban su historia en "el pueblo trabajador y humilde”. Y también había causas didácticas y pedagógicas: el nuevo régimen no toleró ni el interés por las estructuras ni el aprecio por el método intuitivo. Fue precisamente por ello que el franquismo no sólo rompió con estos manuales escolares: también lo hizo con obras como las de J. Bosch- que aunque eran conservadores participaban de una concepción práctica y reflexiva de la historia enseñada, así como del empleo de recursos didácticos que favorecían que el discente participase en la construcción del conocimiento (Castillejo, 2014).

En el Boletín de Educación de Burgos publicado en octubre de 1936 se estableció que la escuela debía fomentar un espíritu nacional fuerte, difundir el catolicismo y favorecer la disciplina y el respeto a la autoridad (García, 2008: 52-53). En consecuencia, la nueva historiografía parecía tener fácil enlace con textos moralistas o apologéticos de carácter religioso y con textos escolares que predicaban el sometimiento al orden vigente. Pero el franquismo fue más lejos. En ese sentido, resulta de interés la figura del editor y pedagogo S. Calleja, cuya obra se desarrolló a lo largo de la Restauración. Como A. Serrano, éste consideraba la enseñanza de la historia como una "escuela de patriotismo". Resulta notable el prólogo de uno de sus manuales escolares, en el que indicaba al discente que "un día la Patria nos llamará para que la sirvamos con las armas" o que "como la Patria necesita también recursos [...] no defraudaremos a la Patria”. Además, "si nos hacen un agravio las autoridades [...] reclamaremos [...] sin salirnos de la ley ni aspirar a la perturbación y a la revuelta [...] ¡No; eso nunca! A la Patria no se la quiere perturbándola” (Calleja, 1902: 181-185). Orden y patriotismo eran valores privilegiados por S. Calleja, pero éste era capaz de reconocer que las leyes antisemitas medievales eran "muy duras" o que los moriscos habían sido tratados con "grandísimo rigor”. En ese sentido, en sus obras podía hallarse un humanitarismo que -junto al más mínimo cuestionamiento del papel histórico de la Iglesia católica o la definición de un espíritu europeo ${ }^{5}$ desaparecería durante el franquismo.

\section{Conclusiones}

En relación con todo lo anterior, resulta evidente que la dictadura franquista no sólo rompió con la tradición progresista, sino que también se desmarcó de los referentes liberales y de cualquier transigencia hacia valores como la integración o la tolerancia. Precisamente por ello, se ha afirmado

\footnotetext{
${ }^{5}$ Ideas defendidas, por ejemplo, por J. Bosch (Castillejo, 2014).
} 
que el franquismo supuso "un retroceso cultural” que llevó a la historiografía escolar a niveles equiparables a los de los años ochenta del siglo XIX (López, 1995: 125-126 y 2010: 12). Desde luego, este hecho aumenta el valor de los libros de texto progresistas publicados durante la Segunda República y posteriormente sustituidos por manuales escolares extremistas que se impusieron en el contexto de un proceso de reorientación radical de la educación que, como se ha visto, también se orquestó a través de cambios drásticos en los programas educativos y la plantilla de docentes (Valls, 1984).

Efectivamente, el hecho de que apenas unos años después de su publicación la dictadura acabase con todos los vestigios del mundo contenido en sus páginas convierte los trabajos que aquí se han analizado en interesantes objetos de estudio. Y no porque las obras de E. García, M. Medina y D. González fuesen revolucionarias, sino porque constituían algunos de los últimos productos de una ya longeva historiografía escolar progresista. En consecuencia, sus páginas permiten rastrear muchas de las innovaciones didácticas y pedagógicas que en los ambientes progresistas se habían ido popularizando a lo largo de décadas. Por último, Historia de España, Mi primer libro de historia y Mi segundo libro de historia son magníficos exponentes de un periodo histórico en el que se soñó con una infancia que no sólo asistiría a la escuela -lo cual no era poco, dadas las elevadas cifras de analfabetismo-, sino que participaría activamente en un proceso de aprendizaje que le permitiría adquirir, de forma crítica, las capacidades y los valores que la harían apta para la vida en sociedad, la política democrática y la construcción de un mundo más justo.

\section{Referencias}

Aguilar, P. (2002). Memory and amnesia. The role of the Spanish Civil War in the Transition to Democracy. Nueva York-Oxford: Berghan Books.

Alario, $M^{a}$ T. (1986). Arte y educación en la obra de Daniel G. Linacero. Tabanque, 2, 51-56.

Altamira, R. (1891). La enseñanza de la historia. Madrid: Fortanet.

Aparicio, J. Ma (1990). Análisis de las propuestas didácticas en las actividades escolares diseñadas por Daniel González Linacero. Publicaciones de la Institución Tello Téllez de Meneses, 61, 471-498.

Bosch, J. (1933). Historia de España. Gerona-Madrid: Dalmáu Carles.

Boyd, C. P. (1997). Historia Patria. Politics, history, and national identity in Spain, 1875-1975. Princeton: Princeton University Press.

Boyd, C. P. (2003). El debate sobre «la nación» en los libros de texto de historia de España, 18751936. En J.J. Carreras y C. Forcadell (Eds.). Usos públicos de la historia (pp. 145-171). Madrid: Marcial Pons.

Calleja, S. (1902). Nociones de Historia. Madrid: Calleja.

Castillejo, E. (2014). Mito, legitimación y violencia simbólica en los manuales escolares de Historia del franquismo. Madrid: UNED.

Cuesta, R. (1997). Sociogénesis de una disciplina escolar: la Historia. Barcelona: PomaresCorredor.

De la Torre, R. (1985). La prensa madrileña y el discurso de Lord Salisbury sobre las Naciones Moribundas. Cuadernos de historia moderna y contemporánea, 6, 163-180.

De Larra, F. J. (1933). Estampas de España. Libro de lectura para muchachos y muchachas. Barcelona: Montserrat.

Escudero, $\mathrm{M}^{\mathrm{a}}$ A. (1999). Cortés and Marina: Gender and the Reconquest of America under the Franco regime. En V. L. Enders y P. B. Radcliff (Coords.). Constructing Spanish womanhood. Female identity in modern Spain (pp. 71-94). Albany: State University of New York Press.

Fernández, J. M. y Agulló, C. (1999). Maestros valencianos bajo el franquismo. La depuración del magisterio, 1939-1944. València: Alfons el Magnànim. 
García, C. (1986). Daniel González Linacero: educador de educadores (1903-1936). Tabanque, 2, 15-28.

García, P. (1986). Daniel González Linacero: la historia para la paz. Tabanque, 2, 29-49.

García, M. (2008). Letras para cambiar el mundo: los libros para niños en las Misiones Pedagógicas. En A. Pelegrín, M ${ }^{a}$ V. Sotomayor y A. Urdiales (Eds.). Pequeña memoria recobrada. Libros infantiles del exilio del 39 (pp. 43-56). Madrid: Ministerio de Educación, Cultura y Deporte.

García, E. y Medina, M. (1934). Historia de España. Madrid: Espasa-Calpe.

Gómez, A. L. y Romero, J. (2007). Escuela para todos, conocimiento académico y geografía escolar en España (1830-1953). Santander: Universidad de Cantabria.

González, D. (1933). Mi primer libro de Historia. Palencia: Afrodisio Aguado.

González, D. (1934). Mi segundo libro de Historia. Palencia: Afrodisio Aguado.

González, D. (1936). Arte español (Estampas). Parte I: de la Prehistoria hasta el Renacimiento. Palencia: Nueva Educación.

Ibáñez, J. y Cemborain, L. (1935). Historia de la Edad Moderna. Madrid: Unión poligráfica.

Izquierdo, J. (1934). Lecturas históricas. Granada: Urania.

Jiménez, F. (2003). Recuento de cooperativas Freinet. En C. Vilanou y J. Monserrat (Eds.). Mestres i exili (pp. 197-219). Barcelona: Universitat de Barcelona.

López, L. y Medina, M. (1978). Tierra leonesa. Ensayo geográfico sobre la provincia de León. Tierra de León, 18, 62-68.

López, R. (1995). El nacionalismo español en los manuales de historia. Educació i Història, 2, 119128.

López, R. (2008). Identificación nacional y enseñanza de la historia: 1970-2008. Historia de la Educación, 27, 171-193.

López, R. (2010). Nacionalismos y europeísmos en los libros de texto: identificación e identidad nacional. Clio \& Asociados, 14, 9-33.

Mainer, J. (2009). La forja de un campo profesional. Pedagogía y didáctica de las ciencias sociales en España (1900-1970). Madrid: CSIC.

Molero, A. (2005). Introducción. En R. Llopis. La revolución en la escuela. Dos años en la Dirección General de Primera Enseñanza (pp. 11-45). Madrid: Biblioteca Nueva.

Muntada, J. (1942). Santa Tierra de España. Barcelona: Altés.

Otero, E. (1982). Las misiones pedagógicas. Una experiencia de educación popular. A Coruña: Do Castro.

Parra, D. y Segarra, J. R. (2018). El aprendizaje de la nación en los regímenes pedagógicos de la España contemporánea. En A. Quiroga y F. Archilés (Eds.). Ondear la nación. Nacionalismo banal en España (pp. 181-204). Granada: Comares.

Pérez, M. (1988). La enseñanza en la Segunda República Española. Madrid: Mondadori.

Pérez, M. (2000). La enseñanza en la Segunda República. Revista de Educación, $\mathrm{n}^{\circ}$ extraordinario $1,317-332$.

Ruiz, P. (2002). La renovación de la historiografía española: antecedentes, desarrollos y límites. En $\mathrm{M}^{\mathrm{a}}$ C. Romeo e I. Saz (Eds.). El siglo XX. Historiografía e historia (pp. 47-76). València: Universitat de València.

Serrano, A. (1942). Yo soy español. Madrid: Escuela española.

Solana, E. (1931). Historia de España. Madrid: Magisterio Español.

Sotomayor, $\mathrm{M}^{\mathrm{a}}$ V.; Cerrillo, P. C.; Sánchez, C. y Cañamares, C. (2016). La censura de libros para niños: 1939-1976. En P. C. Cerrillo y M ${ }^{a}$ V. Sotomayor (Eds.). Censuras y literatura infantil y juvenil en el siglo XX (pp. 53-122). Cuenca: Universidad de Castilla-La Mancha.

Tiana, A. (2016). Las misiones pedagógicas. Educación popular en la Segunda República. Madrid: Catarata. 
Valls, R. (1984). La interpretación de la Historia de España y sus orígenes ideológicos en el bachillerato franquista, 1938-1953. València: Universitat de València.

Valls, R. (1995). Las imágenes en los manuales escolares españoles de Historia, ¿Ilustraciones o documentos? Íber, 4, 105-119.

Valls, R. (1997). La historia enseñada y los manuales escolares españoles de historia. En VV. AA. La formación del profesorado y la Didáctica de las Ciencias Sociales (pp. 37-49). Sevilla: Diada Editora.

Valls, R. (2007). Historiografía escolar española: siglos XIX-XXI. Madrid: UNED.

Valls, R. y López, R. (2011). La didáctica de la Historia y la Geografía como reflexión para la educación actual. Perspectiva histórica. En J. Prats (Coord.). Geografía e Historia. Complementos de formación disciplinar (pp. 189-199). Barcelona: Graó.

\section{CÓMO CITAR ESTE ARTÍ́CULO}

Esteve Martí, J. (2019). Originalidad, desarrollo y destrucción de la historiografía progresista en la educación primaria española (1931-1939). Didáctica de las ciencias experimentales y sociales, 36, 33-46. DOI: 10.7203/DCES.36.12922. 
